\title{
DE LA HISTORIA DE LA FILOSOFÍA A LA FILOSOFÍA DE LA FILOSOFÍA DE JOSÉ GAOS (1900-1969)
}

ABSTRACT About the history of philosophy in philosophy of Jose Gaos' philosophy The philosopher José Gaos said that in universal history the thought of Spanish language has its place and its historic location is presented with the attitude assumed by Spain to modernity, which makes the thought of the Renaissance and the reform have resulted in the grandeur of colonial thought and has had a creative participation in the Counter. However the thought of decadence and independence was born of contact with modern Renaissance science and the philosophy of the Enlightenment, positivism, krausismo and philosophies that represent the latest reactions against modernity. José Gaos was a great exponent of the philosophical doctrines, so that the best way to present the leading ideas of the methods of work of the Seminar for the Study of Thinking Countries Spanish Language was used to cull the fundamental ideas by the thinkers of Latin America and their assumptions, which are always relevant references to their texts.

Keywords: José Gaos, philosophy, Mexico, thought, history of ideas

Palabras clave: José Gaos, filosofía, México, pensamiento, historia de las ideas 


\section{EL CONCEPTO DE “PENSAMIENTO” DE JOSÉ GAOS}

José Gaos es un gran expositor de las doctrinas filosóficas y es capaz de orientar a sus discípulos en México. Es un maestro en el sentido pleno de formarlos, dirigirlos y darles disciplina, con el único método con que esto es posible, con su ejemplo como maestro, esto, por una parte; por la otra, con el trabajo efectivo y personal orientador del discípulo en la investigación filosófica.

En alguna ocasión, cuando Gaos se vio obligado a informar sobre su labor filosófica entre nosotros señala: creo que la parte de mi actividad en México que debo poner en primer término es la dirección de tesis, llevada a cabo en el Seminario para el Estudio del Pensamiento en los Países de Lengua Española, dentro de La Casa de España en México y El Colegio de México en que se transformó. ${ }^{1}$ Ésta es la parte de su labor que él mismo reconoce como la más importante.

Pero éste no la coloca así, sólo por motivos personales, sino porque considera que toda la actividad, de la mayoría, de los transterrados españoles de la filosofía en México, la destacan como la más importante y, a la postre, más benéfica y aunque sólo fuese por esto más importante, es la aplicada al cultivo e investigación del pensamiento hispánico en general y del mexicano en especial. Agrega que él no ha hecho tanto con su enseñanza y sus publicaciones, sino, más bien, en cuanto con haber impulsado a la investigación del pensamiento en México y en general de lengua española, y animado a preservar en ella a los jóvenes ${ }^{2}$.

De tal manera, para Gaos el mejor modo de dar a conocer las ideas directoras de los métodos del trabajo del Seminario para el Estudio del Pensamiento de los Países de Lengua Española era entresacar las ideas fundamentales empleadas por los pensadores de Hispanoamérica y sus hipótesis, los cuales son siempre referencias pertinentes a sus textos, cuidándose de revelar una impresión personal.

El nombre mismo del Seminario motiva a la pregunta ¿Por qué Gaos le llamó pensamiento de lengua española? Porque, según nuestro filósofo, una de las especializaciones de las funciones generales del ser humano, de la vida, de la existencia humana, es el pensamiento, el cual forma parte de la vida humana, que se especializa, a su vez, en filosofía, ciencia y "pensamiento". Especialmente, este último, así entre comillas, porque Gaos busca distinguirlo con toda claridad de la ciencia y de la filosofía en cuanto a la comparación de los temas y las formas de expresión que lo caracterizan y lo distinguen de las otras formas del pensar filosófico.

El "pensamiento", algunas de las veces utiliza las formas, los métodos y el estilo de la filosofía de la ciencia, pero no tiene por tema los objetos sistemáticos y trascendentes de la filosofía, sino, más bien, objetos inmanentes, históricos, humanos, los que no se presentan como los eternos temas posibles de un sistema, sino como problemas de

J. Gaos, 'Los “transterrados” españoles de la filosofía en México', Filosofía y Letras, Núm. 36 (1949), p. 213.

2 Ibid., p. 222-228. 
circunstancia que requieren una solución urgente. Otras veces el "pensamiento" sí tiene por tema los objetos propios de la filosofía, pero no usa sus métodos y estilos, sino que idea y se expresa en formas literarias.

Por esta razón al pensamiento muchas de las veces se le considera como literatura. El pensamiento de lengua española se lo puede caracterizar como filosofía y literatura juntas. Es decir, se estudia no sólo la filosofía de la lengua española, sino el pensamiento de lengua española. El pensamiento se encuentra vinculado como forma de expresión en una lengua. De allí que el pensamiento y la lengua se especialicen en pensamientos y lenguas nacionales llevadas por la vinculación mutua en ellas. Las naciones que participan en una sola lengua tiene una cierta unidad, como lo son las de lengua española, las que forman la unidad de Hispanoamérica ${ }^{3}$.

Desde el comienzo de la Colonia, según Gaos, hay un pensamiento articulado en dos edades en la América española. Una, la del pensamiento de la Colonia de origen importado, como: el erasmismo español, el utopismo de Tomás Moro, el humanismo español y la escolástica española, la que pronto se transformó en tradición decadente; en la otra, se da un pensamiento atento a los problemas planteados por el descubrimiento, la conquista y la colonización, lo cual terminó incorporándose con la filosofía importada.

La otra edad es la iniciada desde fines del siglo XVII, es el pensamiento que irá gestando la Independencia, primero cultural y luego política. Es pensamiento de un espíritu nacionalista creciente, que se caracteriza por una serie de notas y ocupado de ciertos temas de la filosofía hispanoamericana. Hay además en nuestra América desde la independencia, un pensamiento tradicionalista que se caracteriza por defender el pasado anterior a ella y vinculado con la tradición católica.

José Gaos señala que dentro de la historia universal, el pensamiento de lengua española tiene su sitio y su localización histórica, se presenta con la actitud que asume España frente a la modernidad, lo cual hace que el pensamiento del Renacimiento y el de la Reforma hayan traído como consecuencia la grandeza del pensamiento de la Colonia y tenido una participación creadora en la Contrarreforma. En cambio el pensamiento de la decadencia y de la independencia ha nacido del contacto con la ciencia moderna del Renacimiento y con la filosofía de la Ilustración, del positivismo, del krausismo y de las filosofías que representan las últimas reacciones contra la modernidad. Esto quiere decir que en la edad contemporánea los países de lengua española han seguido el curso de la historia de Occidente hasta los días actuales ${ }^{4}$.

La filosofía de Gaos es digna representante de la filosofía moderna en general y de Hispanoamérica en particular. Sin embargo, la modernidad en filosofía de ninguna manera debe ser reducida a una concepción unitaria y unilateral de la filosofía y de la historia a la manera europea, sino vista como modernidad múltiple. José Gaos fue un gran

Cfr. idem, Pensamiento de lengua española, México 1945, p. 19 y ss; idem, Elpensamiento hispanoamericano, México México [s.d.] (El Colegio de México. Centro de Estudios Sociales. Jornadas, 12).

4 Cfr. idem, Pensamiento de lengua..., Caps. IV a IX, p. 15-48; idem, 'Introducción' en idem, Antología del pensamiento de lengua española en la edad contemporánea, México 1993 (Nueva Biblioteca Mexicana, 112). 
conocedor de la historia de la filosofía, de las filosofías modernas, y es uno de los más grandes filósofos y pensadores europeos y americanos del siglo XX. Su filosofía no es sólo una filosofía especulativa, sino que está radicada en la historicidad.

El saber histórico de la filosofía nos muestra en ésta una realidad que entraña este contrasentido: a la idea que la filosofía tiene tradicionalmente de si misma [...] no resulta conforme la realidad histórica de la filosofía - la filosofía entraña una idea falsa de si misma. La idea que la filosofia tiene tradicionalmente de si misma gravita sobre la idea que tiene tradicionalmente de la verdady de la realidad. Verdad es en su primer sentido, la conformidad de una proposición, proferida o simplemente pensada, o de un cuerpo de proposiciones, con la realidad a que toda proposición se refiere, por su propia naturaleza. En su segundo sentido, verdad es la proposición misma o el cuerpo de proposiciones conforme con la realidad a que se refiere. Tradicionalmente, generalmente, se afirma que la verdad es una, que no puede ser más que una [...]. La filosofía es un cuerpo de filosofemas - de proposiciones de la que se predica la verdad. Supuesta la unidad de la realidad - sepredica de la filosofía la unidad. Más a pesar de todo, la filosofía se viene realizando históricamente, en pluralidad de filosofias - cada una de las cuales predica la unidad de la filosofia, a saber, predicando de si la verdad de la filosofía, la filosofía sencillamente, y disputando las demás falsas filosofias, en doble sentido de no ser conformes a la realidad y no ser auténticamente filosofía 5 .

\section{FILOSOFÍA DE LA FILOSOFÍA}

La Filosofía de la Filosofía de José Gaos, en su curso De la filosofía, es un dar razón teórica de la filosofía y ella misma es filosofía e historia. Es una filosofía que sintetiza la fenomenología y la expresión verbal, lo cual lleva "a una fenomenología de la razón” y de ésta a los conceptos y categorías universales. La introducción de la fenomenología lleva a una "teoría de las categorías". Lo que conduce a una filosofía del hombre y a una antropología filosófica, para rematar en una fenomenología y en una teoría de la historia "en su totalidad" de la filosofía y de la filosofía de la historia.

No obstante lo apuntado, para algunos filósofos, la filosofía debe ser concebida como un sistema, ordenado y organizado de ideas que expresan la totalidad del universo, en cuanto es posible que sea captado por la visión filosófica que constituye el sistema. Empero, Gaos reduce a la filosofía a uno de sus elementos y no al esencial, sino al más externo y superficial, identificado como lo inmediatamente dado, vacío totalmente de contenido en su pretendido curso de la filosofía de la historia. Haber pasado por alto la concepción de la filosofía como sistema ordenado en el estudio de la universalidad propia del pensamiento filosófico, parece detenerse en sus componentes minúsculos como son sus expresiones verbales, privando al curso de su objeto más específico: la filosofía como ciencia verdadera.

El análisis filosófico consiste justamente en reducir sus elementos a lo simple de todo sistema, para recomponerlo después, en la síntesis, hasta llegar de nueva cuenta

Idem, Filosofia de la filosofía e historia de la filosofía, México 1947, p. 24-25. 
al todo sistemático. Por este motivo en Gaos la circunstancia de la Filosofía termine en una fenomenología y teoría de la historia de la filosofía y es, lo que parece justificar esta reflexión.

Esto exige por lo pronto un estudio del procedimiento escogido, el análisis mismo de sus supuestos, posibilidades y métodos, que nuestro filósofo no hace en ningún momento. Sin embargo, ésta es una concepción de método y de filosofía bastante generalizada, pero no única. Gaos a partir de la expresión verbal en la fenomenología hace posible valorar y entender la metodología filosófica.

Se puede decir que José Gaos es un revolucionario, no en el plano político y social, sino más bien, en el plano intelectual y filosófico. Fue un ferviente partidario de los procesos y cambios en filosofía y un acendrado crítico de las inconsistencias en la argumentación y la fundamentación filosóficas, no obstante que para él, la filosofía por principio personal, tiene ingredientes históricos. No es tampoco una disciplina más en el marco del sistema. Es la propia filosofía en cuanto un sujeto filosofante concreto, individual, que se pone en cuestión a sí mismo, como objeto de reflexión. De este modo Gaos pone el historicismo de Dilthey al servicio de una filosofía de lo individual y lo concreto.

Sin embargo, Gaos en el estudio de la historia de la filosofía y de los filósofos es intencional, porque en su filosofar y en su filosofía busca el desarrollo de una filosofía personal. Es una "filosofía realista", porque la historia constituye un factor fundamental en la producción de ideas y de filosofías. Define, como Kant, que el fin, el objeto y el método de la disciplina que debe resolver tienen que partir de una Filosofía de la Filosofía, de una teoría de la Filosofía y su fundamento: la historia de la filosofía.

Todo filosofar como actitud personal en torno a la existencia se hace evidente en una situación en el tiempo y en el espacio. José Gaos durante toda su vida realizó una reflexión sobre las ideas de La Filosofía, las cuales están formadas por filosofías y su historia. Para él no existe una Filosofía sino filosofías. Pero lo más importante de destacar es su pretensión por elaborar una "Teoría de la filosofía”, una Filosofía de la Filosofía. Desde su escepticismo filosófico busca hacer una Filosofía de la Filosofía.

Ningún problema le pareció a Gaos más fascinante de todos que el hacer teórico de su especialidad, como es construcción de la perspectiva de una Idea de la Filosofía de la Filosofía.

Estas situaciones no sólo son "históricas" en el sentido de haber entre el escribir una obra filosófica su autor y el conocerla y comprenderla un lector una "distancia histórica", sino que, articulándose unas con otras, en el espacio y en el tiempo, integran toda una "bistoria", la historia" de la Filosofia. Esta historia, por otra parte, no puede ser menos que desconcertante y antitética. Cada filósofo principia de raiz una filosofía... y sin embargo, las filosofías no parecen hacer más que repetir los mismos problemas y unos cuantos tipos de soluciones, de filosofemas, de filosofias - con la novedad a lo sumo de la combinación. Cada una de tales filosofias se conceptúa a si misma de la única verdadera y correlativamente conceptúa de falsas a las demás. $Y$ en suma, las filosofías no van componiendo históricamente un cuerpo de filosofemas reconocido como verdadero por todos los filosofos, como los teoremas y problemas matemáticos respectivamente demostrados y resueltos van componiendo histó- 
ricamente el cuerpo de las Matemáticas reconocido como cuerpo de verdades comunes por todos los matemáticos. Tales características plantean, pues, el problema de la condición de su posibilidad y la causa eficiente de su realidad, o reclama una teoría o Filosofía, como teoría o como Filosofía de la realidad de la Filosofía misma, que es la de la historia integrada por las situaciones constituidas por ella ${ }^{6}$.

El filosofar de Gaos tiene un tema con consecuentes variaciones: se trata de la Filosofía de la Filosofía. Su carácter variable radica en las distintas influencias que tuvo de las corrientes filosóficas de su siglo que lo obligaron constantemente a construir filosofemas que lo conducirían a la necesidad de elaborar una filosofía que explique la Filosofía y que indague sus formas, sus principios de génesis, su proceso de desarrollo y su sentido final.

La filosofía fue para José Gaos la actividad más importante. Ella engloba todo el trabajo teórico del campo de estudio de su especialidad, abriéndole perspectivas nuevas. Para Gaos la filosofía fue una vocación amorosa de entrega completa. Desde su adolescencia ${ }^{7}$ vivió en trato con ella, primero de relaciones amorosas, luego de ejemplar fidelidad conyugal, ${ }^{8}$ hasta convertirla en una cuestión biográfica, en una visión personal de la totalidad, que nunca agota su complejidad. La filosofía termina siendo una cuestión biográfica, el desarrollo de una visión singular sobre el universo y que lleva implícita los elementos más dispares en la consciencia histórica de lo que acontece, como de las experiencias vivenciales del tiempo, el clima, las naciones y el nivel científico.

Así, la filosofía representa una función específica en la sociedad, pero al elevarse por encima de las particularidades de las ciencias y aspirar a una vasta generalización que abarque toda la experiencia de la vida y que la ordene en una imagen clara que le permita plasmar y orientar el actuar en el mundo buscará lo general.

José Gaos señalaba, en sus Confesiones profesionales, cuál era su sentir respecto de la Idea que tenía de la materia de las ideas de la Filosofía y su Historia. La consciencia histórica de la filosofía hace patente la diversidad de sistemas, la pluralidad de posturas, lo cual construye una fisura fundamental y el comienzo de una nueva era.

Las ideas que me he hecho en materia de Filosofia son ante todo ideas acerca de la filosofía misma, ideas de Filosofía de la Filosofía. Dado me es la Filosofía como historia de la Filosofía, integrado por las filosofias. Toda filosofía implica una Filosofía de la Filosofia, por rudimentaria que sea. Hay tantas filosofias de la Filosofia como Filosofias.'

Las reflexiones de Gaos lo llevan a preguntarse si de la filosofía sólo debemos aspirar a un saber histórico, o si el desarrollo histórico de la misma nos lleva a un saber teorético. Lo cual lo conduce inevitablemente a una definición de Filosofía que implica una teoría de ella, in nuce y cómo ésta representaría el amplio despliegue y explicitar el contenido de su definición. Gaos piensa que de la Filosofía sólo podemos aspirar a tener un

6 Idem, Obras completas, Vol. 12: De la filosofía, curso de 1960, México 1982, pp. 406-407 (Nueva Biblioteca Mexicana, 84).

7 Idem, Confesiones profesionales, México 1979, p. 24 y ss.

8 Idem, Filosofía de la filosofia..., p. 28.

9 Idem, Confesiones profesionales..., p. 10 
saber histórico; o si el desarrollo histórico de la misma nos entregase un saber teórico del que se encuentra transida, penetrada en lo más profundo de sus entrañas.

La Filosofía, desde sus orígenes hasta hoy, ha tenido a través de su historia preocupaciones por conocer "la razón de la naturaleza", la "doctrina de Dios", "la búsqueda de la verdad", "el tratado de la naturaleza humana". Por lo mismo se puede decir que Razón, doctrina, tratado, naturaleza llevan, implícitamente, una Filosofía de la Filosofía ${ }^{10}$ y de la Filosofía misma, en su carácter de historicidad, problemas que amenazan constantemente a la verdad de la Filosofía.

La resolución del problema parece haber de estar, pues, en una investigación de la verdad de la Filosofía, o sea de sus objetos y métodos, de sus formas de conocimiento, discurso, prueba, en suma de lo que entra tradicionalmente en el concepto de Lógica lato sensu, que abarca la Teoría del conocimiento ${ }^{11}$.

La propuesta del saber teórico de la Filosofía de Gaos va más allá del mero saber histórico que tiene origen en Dilthey, para aspirar a una Teoría de la Filosofía, una Filosofía que se explique a sí misma, pero también al sujeto filosofante. Filosofía de la Filosofía que debe preguntarse por su sentido más hondo y descubrir la esencia del filosofar, a partir del cual ha de darse la orientación que guíe a la reflexión filosófica.

El tema y el método de filosofar de Gaos se perfilan hacia la idea de una Filosofía de la Filosofía. Sin embargo, Gaos no se hace llamar filósofo, sino profesor de filosofía porque para serlo se requiere - a decir de él - de una filosofía. No porque José Gaos no se haya hecho en materia de filosofía algunas ideas de su propiedad, sino porque, como él apunta, no he desarrollado más ideas en la forma, al parecer, requerida de una verdadera filosofía: sistemática objetiva ${ }^{12}$.

Más allá de esto, la obra filosófica de Gaos tiene las características de una precisión teórica que lleva a connotaciones exactas - quizá porque una parte de su tiempo la dedicó a la traducción de textos de filosofía particularmente alemana -; los conceptos son construidos como bloques sólidos de estructuras semánticas, operativas modernas. $\mathrm{Al}$ igual que la tradición germánica en filosofía, busca depurar de la lengua española los vicios y las ambigüedades hasta lograr precisión y consistencia en su sentido y significado. El uso del español va a adquirir una "dureza" que rompe con las reglas del buen decir, en beneficio de un pensamiento depurado y preciso; a la vez que construye una técnica del lenguaje filosófico de no fácil comprensión.

La Filosofía de la Filosofía de Gaos empieza por un ex abrupto ${ }^{13}$ en el sentido que adelanta algunas razones sobre su contenido, o como él mismo las llama: "anticipaciones de su discurso", aunque no siempre precisadas con el rigor y la inteligibilidad que éste requiere. Es, de este modo, que la supuesta carencia de una filosofía en Gaos, es ponernos alerta y descubrir el método a seguir en su filosofar. Su Filosofía de la Filosofía es dar razón teórica de la filosofía y "ella misma es Filosofía".

$10 \quad$ Ibid., p. 20.

11 Idem, Filosofía de la filosofía p. 116.

12 Cfr. idem, Confesiones profesionales..., p. 9.

13 Cfr. idem, Obras completas, Vol. 12, p. 4. 
Por tal razón, Empezaré - escribe Gaos - por una Fenomenología de la Expresión Verbal. Ésta conduce a una Fenomenología de la Razón y ésta a los "conceptos principales" o "categorias". Éstas son strictissimo sensu los conceptos de "existencia" y "entidad", "finitud" e "infinitud" en todas las combinaciones posibles; $y$, de esta combinatoria resultan como categorias "cardinales" las negativas de "inexistencia" $y$ de "entidad infinita"14.

El desarrollo metodológico hasta aquí presentado llevará a Gaos a una Antropología Filosófica o filosofía del hombre, rematando en una teoría fenomenológica de la historia de la filosofía, o filosofía de la historia de la filosofía.

Gaos pasa por alto el sentido de la universalidad de la filosofía, de la filosofía como sistema, como conjunto ordenado y organizado de conocimientos que expresan una totalidad, para detenerse en los componentes, si se quiere, minúsculos, como son: las expresiones verbales. Sin duda que pensar de este modo el análisis filosófico sería uno de los medios por los cuales se llega a la síntesis de todo sistema. Empero, no puede partirse de cualquier locución sino de una expresión filosófica; de otra forma, resulta difícil valorar la metodología usada. Es obligado partir de las concepciones filosóficas y de aquí llegar al estudio de las expresiones verbales simples.

El método de exposición de Gaos, de acuerdo con sus propias palabras, no puede partir según el orden del ser o según el orden del conocer, porque él particularmente, pensaba que se trataba de una "antinomia" radical; es decir, de una disyuntiva entre términos, entre los cuales no se puede "optar" por "razones" propiamente como tales, o de la "razón pura", lo que sería una contradicción de los términos, "optar" y "razón pura", sino únicamente optar por razones de la "razón práctica", las que son razones de la "razón práctica”, pero, además, son razones personales.

Por las razones prácticas personales va a optar por pensar que el principio de exposición de la Filosofía debe ser el principio en el orden del conocimiento en el sentido de "lo dado" ${ }^{15}$. Las opciones de Gaos son arbitrarias en la razón metodológica de la fundamentación filosófica, lo que puede ser explicado a partir de la concepción que nuestro filósofo tiene de la Filosofía, como aquélla de que ésta es solamente para un sujeto: su autor ${ }^{16}$. Esto nos lleva a la subjetividad, que podría invalidar la propuesta de las reflexiones sobre una Filosofía de la Filosofía, puesto que su propio sentido teórico es incomunicable, lo cual dificulta la posibilidad de la filosofía misma.

Hasta aquí la Filosofía de la Filosofía de Gaos es, por principio, personal. Empero, es necesario hacer notar que ésta tiene elementos históricos; por otro lado, no puede ser reducida a una disciplina en el marco del sistema, sino que es la filosofía misma desde un sujeto filosofante concreto que se cuestiona a sí mismo; es el filosofar de un filósofo que incorpora en su discurso el historicismo diltheyano al servicio de una filosofía de lo individual y concreto y constituido por una fenomenología y una epistemología.

14 Ibid., p. 3 y 4.

15 Ibid., p. 6.

16 Cfr. ibid., p. 427 (también cfr. Con sus idem, Confesiones profesionales...: Las filosofias serían en suma, confesiones personales, de una verdad personal, en cuanto verificable exclusivamente cada una por el correspondiente filósofo, p. 13). 
El filósofo Gaos, en su periplo por la filosofía no puede sustraerse, como él mismo apunta en sus Confesiones, de las influencias del desarrollo de las ideas filosóficas del Siglo XX. Transitó bajo el magisterio de Ortega, de García Morente y de Zubiri los caminos del neokantismo y, previamente, en el bachillerato estudió la escolástica de Balmes. Su vinculación con Xavier Zubiri lo acerca a la fenomenología, porque, a decir de él, uno de los símbolos de la época era estar al día.

En su deambular por la historia de la filosofía, Gaos va paulatinamente perfilando sus preferencias para inclinar su gusto por la fenomenología ${ }^{17}$, la que conoce a fondo, como lo muestra su traducción al español de las Investigaciones lógicas de Edmundo Husserl en 1929, en compañía de García Morente y en 1949 las Ideas relativas a una fenomenología pura.

La doctrina de Husserl es para Gaos una reflexión certera contra el positivismo, el cual no constituía una prueba definitiva de la existencia del orden ideal, sino sólo un momento heurístico relevante en la historia de la fenomenología y la ontología contemporáneas. La reflexión sobre las filosofías precedentes de Hartmann, Scheler, Heidegger, Dilthey y las anteriores al Siglo XX le hacen afirmar: He vivido como la verdad, por lo menos, la escolástica de Balmes, el neokantismo, la fenomenología y la filosofía de los valores, el existencialismo y el historicismo... Aunque, no. Estos últimos ya no puedo acogerlos como la verdad... Ya estaba escarmentando por la sucesión de las verdades anteriores... Pues ¿a qué puede mover semejante sucesión histórica-biográfica de verdades, semejante sucesión vivida, mucho más que la sucesión del pasado sabida por la Historia; a qué, sino al escepticismo? ?1 $^{18}$

La filosofía de Gaos se desarrolla en una lucha enconada con el sentido común y el escepticismo. Empero, ambos, a su manera niegan la validez de la Filosofía. El sentido común sostiene que la verdad la tenemos siempre a la vista, en el sentido de que todo mundo sabe cómo son las cosas, incluso, que toda Filosofía es falsa e inútil.

Es decir, es falsa si contradice el sentido común e inútil si está de acuerdo con él. En cambio el escepticismo, dice, o más bien insinúa, que la razón nos lleva a dudar de todo, incluyendo a la misma razón. Por ello la filosofía no es más que un juego o una pasión inútil, una actividad que no conduce, que no puede llevar a ninguna parte.

Mientras que el sentido común niega la Filosofía desde afuera, el escepticismo la niega desde su propio centro, de la capital misma de éste e intenta mostrar la impotencia de la razón a través de la propia razón. Éste es, precisamente, el extraño papel que le corresponde jugar en sus argumentos. Todo argumento vale para el escéptico y ninguno vale definitivamente. Y dada la importancia de la razón, no tiene mucho sentido para el escéptico la distinción entre el argumento válido y el falaz.

Lo interesante en Gaos radica en que su escepticismo no puede entenderse a la manera tradicional, que lleva a la filosofía a un callejón sin salida, al sostener que ella es imposible; por el contrario, nuestro filósofo hace filosofía y estructura un sistema. Empero, este escepticismo permanece hasta en los últimos trabajos. Por ejemplo, en $D e$

Cfr. idem, Obras completas, Vol. 12, p. 384 y ss.

18 Idem, Confesiones profesionales..., p. 34. 
la Filosofía ${ }^{19}$ terminará sosteniendo la misma tesis de sus Confesiones profesionales, no obstante que desarrolla una serie de propuestas teóricas originales de gran profundidad y en ciertos aspectos, de notable vigor semántico.

El escepticismo en Gaos es más bien un método, un punto de partida para el desarrollo de su argumentación filosófica; porque niega afirmando la validez de la razón, sin desconocer sus vericuetos de subjetividad e irracionalismo, de historicidad y relativismo.

Con su propia vida Gaos nos muestra que la filosofía se reduce a una experiencia personal; no obstante que hizo un gran esfuerzo por romper con la soledad, nunca lo logra, es un ir y venir sobre sus propias ideas en el retiro consigo mismo, es reflexión en la soledad. La soledad es una esfera que Gaos nunca pudo romper, esfera que reduce a su filosofía a la subjetividad ${ }^{20}$ la cual lo conduce al escepticismo, hasta llevarlo a los grandes abismos en que vive filosóficamente, de angustiante soledad y soberbia filosófica.

Así lo expresa en De la Filosofía al final del curso y del libro: Pues bien, puedo decir con sincera y llana verdad que estos finales del curso son justo lo único de todo él que se remonta a los principios de mis relaciones con la Filosofía: el encuentro mismo con ella [...] esto lo he contado en mis Confesiones Profesionales. [...] La historia de la Filosofia originó - lo que ha originado siempre, también en mí: el escepticismo acerca de cada una de las filosofias... Quizá ya no a pesar del escepticismo acerca de cada una de las filosofias, sino justo por él, desde pocos años después se me planteaba y a con plena conciencia, en sus términos propios, técnicos podria decir con el problema de la Filosofía... debo decir que los esfuerzos por resolverlo satisfactoriamente para mi han sido los esfuerzos por resolverlo satisfactoriamente para mi han sido los esfuerzos a unos más filosóficos y personales de los treinta y cinco a cuarenta años de mi vida que puedo contar desde el dia de hoy hacia atrás... Bajo la especie de tal problema, la soberbia de la filosofía me contagió a revisarlo todo por mi como si estuviese destinado a ser el autor de toda una filosofía propia ${ }^{21}$.

Esto nos permite decir que la Filosofía de la Filosofía surge, para Gaos, cuando un hombre concreto es volcado hacia la reflexión filosófica sobre su vida, la existencia, la historia y, después de descubrir su inútil obstinación termina reconociendo que todo cuanto pretendía no es ni siquiera comunicable ${ }^{22}$ a los demás, salvo algunos aspectos de la ciencia y de la lógica.

José Gaos, seguidor de algunas de las reflexiones de su maestro Ortega, desarrolla su filosofía en dos ideas eje: el perspectivismo y el historicismo; el primero plantea que el sujeto cognoscente sólo puede captar la realidad desde una perspectiva, lo cual imprime un cierto subjetivismo a todo conocimiento. Mientras que Ortega acepta, de cierto modo, el conocimiento absoluto e intenta dar un paso hacia adelante del relativismo,

19 Cfr. idem, Obras completas, Vol. 12, p. 417-418.

20 Cfr. idem, De antropología e historiografía, México 1967, p. 31-33 (Cuadernos de la Facultad de Filosofia, Letras y Ciencias, 40).

21 Idem, Obras completas, Vol. 12, pp. 417-418.

22 Cfr. idem, Confesiones profesionales..., p. 14. 
Gaos se queda con la visión relativista porque los hombres tienen que enfrentar las condiciones de existencia, y esto sólo es posible en la historia, y la historia no construye hipótesis universales.

El segundo puede entenderse desde la visión gaosiana como un elemento complementario del primero y tiene relación con principios de distinta naturaleza: racionales, axiológicos, políticos los que son dependientes, a su vez, de la época en que se dan. Todo esto lleva inexorablemente a un subjetivismo infranqueable. Perspectivismo e historicismo pueden ser entendidos como un relativismo que tiene como presupuesto el absoluto y los principios de la razón misma.

Así, la concepción filosófica de Gaos muestra distintas influencias, entre las que se destacan, además de sus maestros españoles arriba citados, particularmente Dilthey, Husserl y Heidegger, muy especialmente el primero, como lo confesó alguna vez. No obstante esto, su filosofía es, en muchos aspectos, original. Ya desde sus escritos ${ }^{23} \mathrm{de}$ 1945 tenía presente en su filosofar que la filosofía del hombre debe contemplar a éste en su propia y personal concreción. Esto le permite aseverar que el filosofar es antropológico o quizá, más precisamente, un personalismo con profundos rasgos existencialistas.

La Filosofía es en este sentido una caracterización del hombre, de lo propio, de aquello que diferencia a una persona de otra, eso que hace expreso lo peculiar de cada sujeto, distinción que da la diferencia de los demás seres, por lo que su filosofía se la puede considerar, más bien, como la Filosofía del Hombre o una Antropología Filosófica. De tal modo, la filosofía da razón del hombre en cuanto lo que él es. La Antropología filosófica redundaría en el hombre en cuanto objeto de la definición de él y del desarrollo de ésta ${ }^{24}$.

Sin embargo, Gaos considera que el hombre, no obstante que da razón de todo, incluso de Dios, no la da de sí mismo, en la medida que cualquier intento por conocer los "conceptos metafísicos" y su alcance, como por conocer qué es la naturaleza humana en general, es acotar lo incognoscible ${ }^{25}$. Esta actitud de Gaos tiene un contexto común que lo determina: su concreción histórica, su temporalidad, dependiendo de la situación en que cada individuo se halla. Exclusivamente desde aquí es posible determinarlo no sólo en lo general, sino según su historia.

En Gaos no puede existir una filosofía en abstracto, puesto que hay tantas filosofías como sujetos filosofantes. Así la filosofía y el filosofar en su autenticidad tienen que discrepar necesariamente de las demás formas; por ello interrogarnos por el qué de una filosofía es preguntar por un filósofo de carne y hueso, es decir, es una confesión profesional, es también una actitud de independencia tanto de la tradición como de las creencias de la comunidad.

Esta orientación de lo "Concreto de la Filosofía" en Gaos, le abre el espacio para articular la Filosofía con la filosofía americana, la cual no se funda en principios de

23 Cfr. idem, 2 exclusivas del hombre. La mano y el tiempo, México 1945.

24 Idem, Del hombre (curso de 1970), México 1970, p. 15 (Publicaciones de Diánoia).

25 Cfr. ibid., p. 484. 
carácter general, sino en la circunstancialidad americana dentro de la cual desempeña un papel indiscutible la Lengua Española. Es por ello que a "nosotros", los "hispano-americanos" - como solía llamarnos Gaos - se nos impone la obligación de estudiar nuestra vida con su radical historicismo de los principios de la filosofia; con su bistoria de los principios, de la filosofía en primer término; la historia que es la realidad de la historicidad humana y que es cabo el actual de nuestra vida con su historicismo ${ }^{26}$. Lo cual lo lleva a reafirmar que todas las cosas humanas y el hombre mismo tienen una historia, porque la esencia del hombre, como escribe Dilthey, es por naturaleza historia.

A partir de la óptica de la historicidad humana va ubicar a América como parte de Occidente, correlato necesario aunado a la otra parte del mundo, Oriente. No obstante el problema que le ocupa, busca mostrar la posibilidad de una filosofía americana. Esto lo remite al problema de la nacionalidad, la que adquiere su verdadero sentido con la unidad de la lengua, porque, según Gaos, la adopción de la Lengua Nacional es la expresión y la función análogas de la aparición de la nacionalidad en filosofía ${ }^{27}$.

Tal fenómeno se muestra en la historia de la filosofía, pero además hace específico un carácter especial de reflexión. La reflexión sobre este tema concreto de la circunstancia americana y su filosofía hace decir a Gaos: América será la filosofía de quéamericanos, es decir hombres en medio de la circunstancia americana, arraigados en ella, hagan sobre su circunstancia ${ }^{28}$; la de los hispanoamericanos dentro de una determinada realidad histórica e inclinados a una peculiar manera de pensar.

Para Gaos todo filosofar como actitud personal referida a la existencia se hace evidente en un tiempo y un espacio. Aspectos que no sólo pueden considerarse como históricos, en el sentido de la escritura de un autor y su relación con un lector, sino además, en su articulación recíproca, lo cual integra una historia, la Historia de la Filosofía. Así cada filósofo inaugura una filosofía; empero, a decir de Gaos, las filosofías no parecen hacer más que repetir los mismos problemas y unos cuantos tipos de soluciones, de filosofemas de la filosofía, con la novedad, a lo sumo, de combinación conceptual.

Cada una de tales filosofías se conceptúa a sí misma, como la única verdadera, y correlativamente, conceptúa como falsas a las demás. En suma, las filosofías no van componiendo históricamente un cuerpo de filosofemas reconocidos como verdaderos por todos los filósofos, como los axiomas, teoremas y problemas matemáticos ${ }^{29}$.

No obstante esto, la historia de la filosofía no es caótica; tiene unidad dentro de la pluralidad, unidad no tanto en los filosofemas, sino en los conceptos y las categorías que los constituyen, tales como ser, ente, esencia, sustancia, Dios, hombre, existencia los que a su vez determinan el género de las distintas filosofías, que pueden ser ontológicas, antropológicas, existencialistas, historicistas, materialistas e idealistas, todo lo cual son factores suficientes para extender la tesis a toda la historia de la filosofía. La historia de

\footnotetext{
26 Idem, Pensamiento de lengua..., p. 18.

27 Ibid., p. 34 .

28 Ibid.

29 Cfr. idem, Filosofía de la filosofía..., p. 446.
} 
la filosofía es para Gaos un método de trabajo y un órgano de su filosofar, pero dentro y desde una circunstancia personal.

Cabe señalar que Gaos es un filósofo muy cauto en su reflexión filosófica; nunca da un paso en un tema filosófico sin una previa información suficiente; hay en él una avidez increíble que lo empuja a buscar permanentemente nuevos conocimientos. Sin embargo, para concluir, diría que a pesar de que las reflexiones filosóficas de Gaos representan una postura filosófica personal, sus investigaciones teóricas y filosóficas muestran un exhaustivo inventario de problemas filosóficos y de soluciones dadas por diversos autores, donde se manifiesta un amplio conocimiento de los sistemas, los que son sometidos al análisis exhaustivo en cuanto a sus procedimientos críticos. Gaos fue un filósofo consciente de que la filosofía que se ejerza está determinada por la clase de hombre que se es y hace gala de este principio al convertir al filosofar y a la filosofía en una actividad personal, es decir, subjetiva.

Empero, a pesar de todo lo anterior insistiría que, la filosofía de José Gaos de ningún modo lleva irremisiblemente a su destrucción, sino, más bien, a su fortalecimiento y a la confianza en la metafísica. Su filosofía es un buen programa crítico que busca por todos los medios no caer en el error onticida, es decir, en la muerte del Ser y de la Metafísica. Por lo mismo son inútiles las mortuorias declaraciones, como ninguna letal superación. Gaos aceptaría la palingenesia filosófica, pero de ningún modo declara su epitafio, ni dejó en paz a los vivificantes sepulcros que constituyen a la Filosofía. Es necesario acercarse a la filosofía a través de su historia, desde un intento problematizador de la razón y del conocimiento. Es decir, de la Filosofía misma. Porque cada vez que se ha intentado argumentar en su contra sólo se ha logrado construir un interminable eslabón de la cadena. De allí la inutilidad de declarar la muerte de la filosofía.

\section{BIBLIOGRAFÍA}

Gaos J., 2 exclusivas del hombre. La mano y el tiempo, México 1945.

Gaos J., Confesiones profesionales, México 1979.

Gaos J., De antropología e historiografia, México 1967 (Cuadernos de la Facultad de Filosofia, Letras y Ciencias, 40).

Gaos J., Del hombre (curso de 1970), México 1970 (Publicaciones de Diánoia).

Gaos J., Filosofia de la filosofia e historia de la filosofia, México 1947.

Gaos J., 'Introducción' en idem, Antología del pensamiento de lengua española en la edad contemporánea, México 1993 (Nueva Biblioteca Mexicana, 112).

Gaos J., 'Los “transterrados" españoles de la filosofía en México', Filosofía y Letras, Núm. 36 (1949).

Gaos J., Obras completas, Vol. 12: De la filosofía, curso de 1960, México 1982 (Nueva Biblioteca Mexicana, 84).

Gaos J., Pensamiento de lengua española, México 1945.

Gaos J., El pensamiento hispanoamericano, México [s.d.] (El Colegio de México. Centro de Estudios Sociales. Jornadas, 12). 
Prof. Mario MAGALlón ANAYA - Profesor de Educación Primaria, Licenciado y Maestro en Filosofía y Doctor en Estudios Latinoamericanos (Filosofía), por la UNAM. Especialidad en Filosofía Latinoamericana, Filosofía Política e Historia de las ideas en América Latina. Investigador titular "C" de tiempo completo definitivo en el Centro de Investigaciones sobre América Latina y el Caribe, CIALC/UNAM; es profesor de licenciatura y posgrado en la Facultad de Filosofía y Letras de la UNAM. 